\title{
Lenguas e identidades El acento extranjero y la construcción de las categorías de los locutores en los relatos autobiográficos
}

\author{
Christine Deprez \\ Profesora de Lingǘstica. Universidad de Paris V. Facultad de Ciencias Humànas y Sociales - Sorbona
}

\section{Introducción}

S e predijo que "el siglo XXI sería el siglo de las identidades". Sin embargo, el vínculo entre lengua e identidad no es nuevo. En la Biblia, los episodios de la Torre de Babel y del Shibboleth se ocuparon de este aspecto. Actualmente, la identidad es una noción muy utilizada en las Ciencias Humanas y en la política y su empleo es cada vez mayor en medios donde se conceptualizan las identidades colectivas emergentes o conflictuales (identidad nacional, étnica, cultural); la individual (identidad personal, carta de identidad) o las débiles: búsqueda de identidad, crisis de identidad... Los sociólogos explican esto como consecuencia del paso de una sociedad tradicional, donde las identidades son estables y establecidas de antemano, a una sociedad más móvil e individualista, donde cada uno puede (ien teoría!) construir y conquistar un lugar en un entorno menos determinista.

Sin embargo, la extensión en el uso de este término va a la par de una fuerte evaporación de su sentido: nebulosa semántica con carácter mal definido; es la palabra que la acompaña y el contexto de sus diferentes empleos los que precisan su sentido, así como los campos disciplinares que convoca: filosofía, política, antropología, psicología, etc.

\section{Asociación de términos y construcción de un punto de vista}

En este escrito consideramos la relación "lengua e identidad" como la yuxtaposición de estos dos términos, que enuncia un punto de vista sobre la identidad del individuo o del grupo, marcada esencialmente por la lengua o en la lengua (punto de vista lingüístico y cognitivo) pero también en las prácticas discursivas en acción, localizadas y observables en las interacciones (puntos de vista sociolingüístico y pragmático).

El punto de vista lingüístico encuentra su fundamento en las posiciones culturalistas de Whorf (1956) quien, a partir de la descripción de las lenguas amerindias, mostró cómo cada lengua fracciona el mundo a su manera y por su uso: se conoce su trabajo sobre la metafísica de los Hopis llevado a cabo a través del estudio de la lengua y de la observación de los comportamientos de los locutores, así como el impacto que estos trabajos produjeron para la formulación estructuralista de Lévi-Strauss (1966). En esta perspectiva, la lengua refleja para el descriptor extranjero (el otro) la visión del mundo de sus locutores y se constituye en la principal vía de acceso a las creencias y los valores que ella ¿vehiculiza?, ¿manifiesta? o ¿configura? 
Sin duda, es necesario buscar detrás de estos verbos, tres concepciones diferentes sobre la relación entre lengua e identidad cultural: la primera (la lengua vehiculiza) concibe la lengua como un simple "medio de comunicación"; la segunda (la lengua manifiesta) presupone que las formas de la lengua moldean la visión del mundo, lo que significa un retorno hacia el estudio de las formas que nos dan el acceso (según Worf, op. cit.); la última concepción (la lengua configura) sugiere que la lengua participa indefinidamente en la constrúcción de los contenidos que ella expresa.

El punto de vista sociolingüístico que se interesa por los locutores y las prácticas discursivas (usos de la lengua en situación) aborda la cuestión de manera diferente:

- De una parte, a través de las palabras que una sociedad utiliza o crea para denominar y circunscribir sus objetos sociales (instituciones, grupos, etc.), la lengua permite ver sus valores, su. sistema de categorización social y su evolución.

- De otra parte, a través de las "maneras de hablar", busca poner en correspondencia las marcas lingüísticas con los grupos de locutores para las cuales ellas son específicas; por ejemplo, los acentos regionales o los acentos extranjeros, que se abordarán más adelante,

- Finalmente, es también en la interacción con el otro como se van a precisar las marcas identitarias.

Después de estas aclaraciones sobre la dupla "lengua e identidad", es necesario volver atrás para convocar diferentes concepciones sobre la noción de "identidad", especialmente las más fre- cuentes. Para lograrlo, me gustaría presentar rápidamente las dos grandes oposiciones clásicas.

\section{"identidad" en singular / "identidad" en plural}

Utilizado en singular, el término remite, de una parte, al carácter único de cada persona, así como a su estabilidad, su constancia, su permanencia en el tiempo. Es ella la que garantiza socialmente la toma en cuenta de ciertos identificadores presentes en el famoso "documento de identidad", o mejor aún, biológicamente lọ que se encuentran en el capital genético inscrito en el ADN. Encontrará su expresión lingüística en el "sí" o en la denominación (el nombre, el apellido) y su expresión psicológica en la noción de "carácter" o de "personalidad". Nos lleva a pensar el sujeto como "uno"; el término reenvía a la vez a su unicidad y a su unidad.

El filósofo Paul Ricoeur (1990) propone pensar la identidad personal como el lugar de la confrontación entre eso que él llama de una parte la "mêmeté" (idéntico) que reenvía a la permanencia del individuo como sustancia en el tiempo y, de otra parte, "ipséité" (ipse) que reenvía a las disposiciones duraderas de quien se reconoce como persona única en su género y la hacen diferente. de los otros. El punto de vista esencialista que remite con más profundidad al uso de identidad en singular, se funda sobre una representación de sí mismo y de su propia continuidad, representación siempre más o menos ficcional y por lo tanto absolutamente necesaria para la inteligibilidad de sí mismo, de los otros y del mundo que lo rodea.

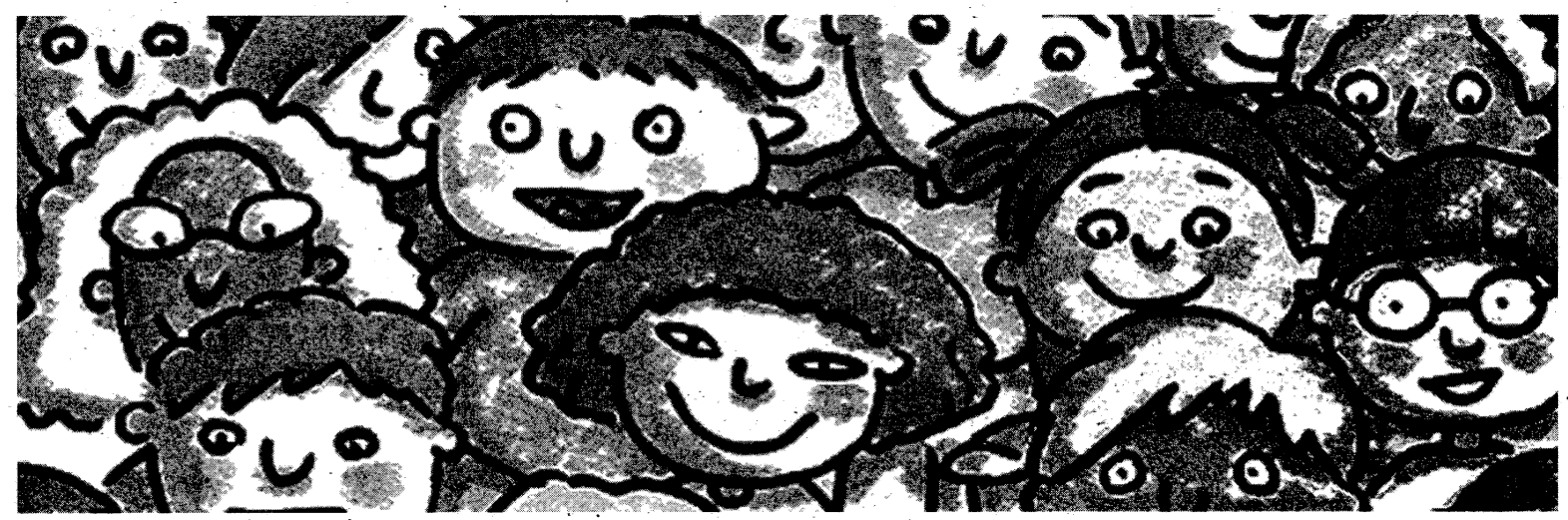


Señalar "identidades" en plural remite a una concepción muy diferente de la precedente. En un momento dado, cada uno de nosotros hace de la experiencia cotidiana una pluralidad de identidades materializadas en roles y en funciones diversas: madre, esposa, profesora, sindicalista, etc. Cada uno de estos roles es entonces percibido como una identidad diferente (aunque compartidas por otros), con puntos de vista, acciones e interacciones específicas que se concretizan en actos de lenguaje y en formas lingüísticas apropiadas (en los cambios de lengua, o de estilo, por ejemplo).

La diversidad y la acumulación de estas identidades diferentes provocan en las sociedades contemporáneas eso que Gergen (1997) llamara con humor "el yo saturado". Señalemos que la presentación según la cual nosotros asumiríamos diferentes identidades (es decir, las formas especialmente verbales que ellas requieren) como diferentes costumbres ("uno se cambia de cachucha”, según una expresión francesa) evoca la idea extraña de identidades intercambiables exteriores al sujeto donde ellas cohabitarían, aunque se acomoda mejor con la idea de marcas identificatorias que para muchos serán marcas de lenguaje a menudo convergentes con marcas corporales, posturales y de vestuario.

\section{"identidades recibidas" / "identidades construidas"}

Las identidades recibidas son en primer lugar aquellas que nos son transmitidas por nuestro grupo y principalmente por nuestra familia, especialmente a través del lenguaje desde el nacimiento: su historia, su cultura, sus tradiciones y los proyectos que nos conciernen. Es una identidad social, que nos inscribe en una filiación, nos asigna un lugar en una estructura existente (en un grupo, por ejemplo), nos otorga un nombre y un apellido, etc. Nos inscribe también en una (o unas) lengua(s), en un lugar de nacimiento y, en consecuencia, en una nacionalidad.

Bourdieu (1982) insiste sobre esta herencia y la precisa a través de las nociones de "heixis" (actitudes del cuerpo) y de "habitus" (comportamientos adquiridos y situados socialmente), que él desarrolla a propósito de la cultura y del lenguaje, cuando habla del "capital lingüístico" y del valor de las diferentes variedades en el "mercado lingüístico". Agregamos que al lado de las identidades objetivadas como las anteriores, se encuentran también las identidades esperadas, dibujadas por los deseos y los proyectos de los padres. Al niño se le habla desde antes de su nacimiento: ¿a quién se parecerá? Se le busca un nombre, un apodo, se imagina su carácter (y antiguamente su sexo) según la forma del vientre de su madre y de sus movimientos.

En el análisis del discurso, estas identidades se reconocen especialmente a través de las formas, de hetero-categorizaciones, es decir, de categorizaciones sobre sí, producidas por los otros y que conciernen tanto al carácter personal como a las características del grupo en el cual se está ubicado. El maestro categoriza a sus alumnos como: los “tímidos”, los “traviesos", los “marroquíes", los "chinos" y les atribuye comportamientos verbales, en función de su experiencia anterior o de los discursos del medio, comportamientos que; por otra parte, él puede reforzar a través de su práctica (cf. el famoso efecto Pygmalion).

Las identidades recibidas son lo suficientemente estables aunque no inmodificables: son trabajadas y retrabajadas por las interacciones que permiten la evolución o confirmación de estas hetero-categorizaciones. Igualmente permanecen con el sujeto a lo largo de toda su vida. $Y$ es a este trabajo al que uno se refiere cuando habla de "identidades construidas", de "estrategias identitarias", de "producción de identidad", expresiones que.remiten más a menudo al proceso que al producto.

Estas identidades construidas se elaboran en las acciones y en los discursos de cada uno. Sobre la base de las identidades recibidas, uno las transforma y las negocia en las interacciones sociales y verbales en las cuales está implicado. Esta concepción dinámica de las figuras identitarias debe mucho a la puesta en escena y a la teatralización de los comportamientos, que han sido muy bien descritos por Goffman (1973). La sociolingüística interaccionista que él ha inspirado aprehende esta imágen de una identidad que se construye en situación en la interacción y en la coenunciación. 
Paul Ricoeur, quien ha consagrado tres volúmenes al tiempo y al relato y posteriormente otro al relato autobiográfico ${ }^{1}$, desarrolló el concepto importante de "identidad narrativa", en el cual se han interesado diversas disciplinas y algunos teóricos lo han adoptado, como lo ha hecho el psicólogo cognitivista americano Jerome Bruner. Se puede decir, en general, que los investigadores que practican, desde hace mucho tiempo, la anamnesis, la entrevista de carácter biográfico o el relato de vida, han acogido de manera favorable la propuesta de Paul Ricoeur y la han enriquecido desde sus aproximaciones disciplinares.

Sin embargo, al unir "lenguas e identidades" se trata de mostrar la centralidad de la cuestión del lenguaje en referencia a la identidad, puesto que no hay identidad sin las palabras, de sí sobre sí, de sí sobre los otros o de los otros sobre sí. Toda toma de la palabra nos constituye como sujetos hablantes, a través del "yo" y contiene marcas de la enunciación. Para ilustrar conjuntamente estas cuatro aproximaciones de la identidad: individual, colectiva, heredada y construida, se tomarán dos ejemplos extraídos de nuestros estudios sobre el bilingüismo y las migraciones para analizar el acento extranjero y las categorizaciones.en los relatos de sí.

\section{El acento}

Para este texto he escogido algunas personas provenientes de regiones rurales del norte de Portugal que han venido a instalarse en Francia. Esta emigración se realizó a menudo en pareja entre los años 60 y 70: los portugueses huían entonces de la miseria de los campos y de la dictadura de Salazar. Se instalaron sobre todo en la Región parisina; los hombres se especializaron en trabajos de construcción y las mujeres en servicios; los hijos han sido escolarizados en Francia. La mayor parte de las familias toma un descanso de al menos un mes durante el verano en Portugal donde muchos de ellos han construido una casa.

El portugués es una lengua de inmigración cuyo uso se mantiene en las familias y se trans-

\footnotetext{
1 Soi-même comme un autre, Paris, edt. Du Seuil, 1990.
}

mite a los hijos. Mucho tiempo se ha consagrado a las cuestiones de adquisición de la lengua en el país de residencia. Los estudios más recientes se interesan en los cambios observados en la lengua portuguesa, especialmente en el acento.

La voz es algo singular, que identifica y caracteriza a la persona y permite reconocerla, entre todas, por sus allegados: cada voz es única y toma su timbre y su textura en el aparato respiratorio y en los órganos de fonación de aquel o de aquella que habla. La voz, como el cuerpo, puede ejercitarse, trabajarse y cambia con el transcurso del tiempo, guardando una cierta continuidad, una cierta "mêmeté" (identidad) (salvo cuando los adolescentes cambian de voz): muy ligada a las emociones, al "carácter" (a la timidez, por ejemplo), moldeando de esta manera la expresión. El lenguaje se construye en y por las emisiones vocales propias de cada uno (una), desde el nacimiento. ¡Aunque el acento es imitable!

De otro lado, sabemos que todas las maneras de pronunciar una misma lengua diver-

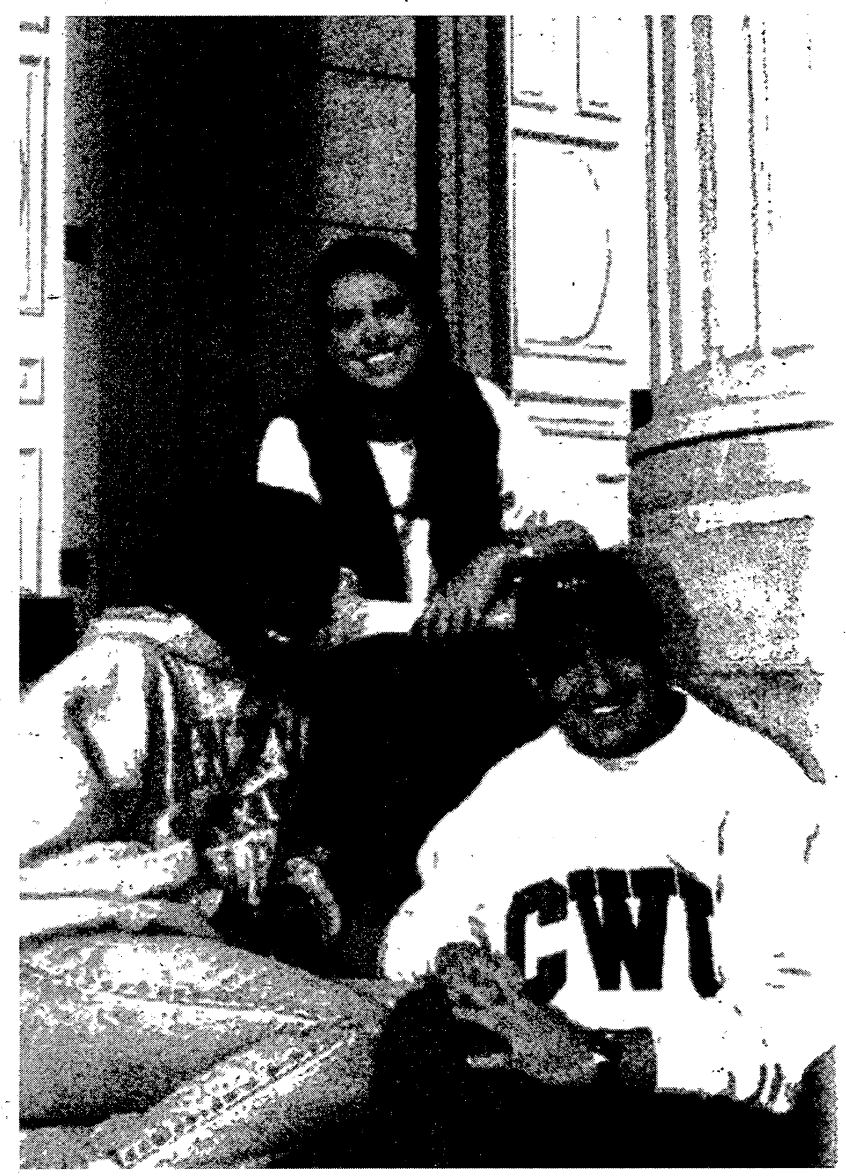


gen según la edad, el sexo, el grupo y la región. Cuando se asocia un acento o una manera de pronunciar con un grupo identificable geográfica o socialmente, "tratamos" en un mismo y doble movimiento interpretativo, la lingüística y la sociolingüístiça: "quién" dice "qué", donde, el "qué" del enunciado cuya materialidad sonora es a la vez el significante de lo lingüístico y de lo semiótico que comprometidos en una misma actividad cognitiva de reconocimiento, de memorización o de descubrimiento nos instruye sobre el "quién".

De esta manera, aun antes de venir a Francia, las jóvenes parejas portuguesas de los años sesenta hablaban su lengua (una variedad del portugués hablado en el Norte) con un acento que decía sobre su origen regional, rural, tanto como lo hacía el cuerpo y la cara del campesino marcado por los trabajos del campo.

Es entonces sobre esa materialidad socializada y traducida en signos, es decir, en formas simbólicas observables, participantes en la definición categorial que interviene la atribución de los valores o de los estigmas propios de cada cultura. Es este mismo acento que los padres han guardado y transmitido a sus hijos en la migración y es también este acento por el cual son "identificados". como "emigrantes", de un lado de la frontera y como "inmigrantes" del otro. Notamos el paso que se hace en general de la identificación y de la categorización, no sobre un solo rasgo fácilmente aislable, sino sobre niveles de registros diferentes: prosodia, fonética, voçabulario, posturas, vestido, maneras de comportarse en sociedad... sobre aquello que los humoristas y los imitadores han comprendido perfectamente y que constituyen su blanco.

$\mathrm{E} 1$ aprendizaje de la lengua, junto con el alojamiento, los papeles y el trabajo, es una de las grandes pruebas que les espera a los inmigrantes. Este aprendizaje de una nueva lengua, que es más difícil a la edad adulta, se realiza la mayor parte del tiempo en el contacto con los franceses o con otros inmigrantes; ellos conservarán largo tiempo, a veces durante toda la vida, el acento, este acento que los va a hacer categorizar como "extranjeros" por parte de los "autóctonos".

Este acento es, en parte, heredado y produce las interferencias (transferencia de costumbres acústicas y articulatorias) del portugués, lengua materna, sobre el francés; fenómeno en el que la mayor parte de nosotros hemos tenido la experiencia cuando hemos aprendido una lengua viva en la escuela. Uno descubre el acento portugués, en portugués y en francés, sobre todo en las sibilantes fricativas finales, sobre las vocales y los. diptongos nasales, sobre la pronunciación de la $/ \mathrm{r} / \mathrm{y}$ de la $/ \mathrm{a} /$ anterior.

Sin embargo, al escuchar las grabaciones, estamos lejos de observar un acento portugués estable que sería el producto mecánico, previsible inspirado por la lingüística contrastiva. Las variaciones entre individuọs son muy importantes, especialmente entre los hombres y las mujeres. Las mujeres, como empleadas domésticas y madres, están más en contacto con la población francesa y más cerca de sus hijos y de la escuela. Por otra parte, ganan más al inscribirse con sus hijos, en la modernidad urbana y se muestran más competentes en francés y mucho más hábiles en el uso alterno de dos lenguas en las conversaciones familiares. Se ve entonces que a través del aprendizaje de una lengua extranjera (el francés), ellas dan a entender a la vez su historia, la de la emigración rural pero también su futuro que se va a jugar con el de sus hijos.

Los hijos han nacido o llegado jóvenes a Francia, han sido escolarizados en las escuelas públicas de su barrio y su francés no se diferencia mucho del de los niños franceses de su edad y del mismo medio social: ciertos investigadores señalan a lo sumo, una más grande "inseguridad lingüística" què se encuentra en las poblaciones con una fuerte movilidad social ascendente y que es también propia de los niños que no han nacido 
en la lengua y que, por tanto, no se sienten a menudo legitimados en su uso. Pero, ¿qué pasa con la otra lengua, el portugués? Esta lengua a menudo hablada en la casa y "refrescada" regularmente en su país, durante las vacaciones, debería entonces inscribirse sin pena en su repertorio lingüístico para hacer de ellos niños bilingües: el francés que acumula los valores funcionales, como instrumento de la comunicación, y el portugués, que atesora los valores simbólicos e iden-. titarios heredados.

Pero la identidad lingüística no se reproduce en nuestras grandes ciudades, sino que se construye a partir de "lo ya dicho", y también con otros parecidos-próximos (François, 1990), especialmente los jóvenes y los grupos de pares. Se comprende bien que nunca, salvo por burla, un niño extranjero habla con el acento de sus padres, con quienes le es imposible asemejarse e identificarse. Al contrario, él construye con sus compañeros una manera de hablar, adopta el acento del grupo "emblemático" (comunidad de prácticas), las interjecciones, los tics de lenguaje que son propios de ellos y con quienes se reconoce y se diferencia. Es posible entoncés "convocar" las palabras de otras lenguas, entre ellas las de los padres. Numerosas películas populares (La Haine, L'Esquive, Taxi) y documentales se han inspirado en esta situación. Los estudios sobre las lenguas étnicas, especialmente la del VAA (Afroamericano vernacular) han sido como una mancha de aceite en Francia en donde la "lengua de los jóvenes" se ha convertido en objeto de estudio corriente e institucionalizado por los profesores universitarios, las revistas, los coloquios.

También es claro que la variedad dialectal y el acento de los padres en su lengua maternạ, no sea un modelo interiorizable y ásimilable por los jóvenes "franco-portugueses". Esta lengua parental o familiar conlleva la triple marca identitaria de una región, de una época (la de la juventud de los padres) y de una historia reciente; la del contacto con el francés durante la inmigración. Los estudios realizados por Helena Correia (ref), basados en observaciones etnográficas muy finas en muchas generaciones de una misma familia, en Francia y en Portugal, ponen de relieve tres tipos de realizaciones en los jóvenes:
- Hipercorrección: hablar en portugués bastante puro a nivel de la pronunciación, es decir, un portugués estándar y muy académico, aprendido o reaprendido formalmente.

- El ocultamiento: evitar hablar en portugués y preferir el francés, aun en el mismo Portugal.

- Una cierta variación en la pronunciación portuguesa de la sibilante fricativa que tendería a realizarse como con una $/ \mathrm{s}$, especialmente en las finales de los sustantivos en plural. La explicación según la cual se trataría de una interferencia del francés no es adecuada puesto que el francés dispone de una oposición /s/ -/S/ ("s" y "ch", respectivameñte).

La autora propone otra hipótesis: los jóvenes tenderían a èvitar este fenómeno portugués fuertemente estigmatizado por los franceses, del cual se sirven para burlarse de los portugueses. Los jóvenes a través de esta pronunciación se separarían del grupo de los inmigrantes al cual pertenecen sus padrés. Recordemos que la lengua portuguesa se transmite generalmente en Francia de una generación a otra. Es entonces la respuesta identitaria de la segunda generación que se construye en un proceso de continuidadmodificación (F. François, 1990) frente al habla de sus padres.

\section{El acento de los otros: un poco de historia}

\section{La imagen del otro a través de su lengua}

En un libro titulado El espejo de Heródoto, ensayo sobre la representación del otro, François Hartog (1980) nos muestra cómo los griegos de la época clásica se representaban a los otros (a los no griegos). Para ello toma por objeto de estudio la "figura del bárbaro", tal como ella aparece en las Historias de Heródoto, texto sobre las guerras médicas, escrito en griego y destinado a ser leído por los griegos.

El historiador francés precisa de entrada, en su título, que la forma como los griegos hablan de los otros es una contrafigura que encierra de manera negativa, el espejo de su propia representación de ellos mismos, la cual ayuda, por otra parte, a definir y a unificar por contraste. Por lo 
tanto, el bárbaro designaba en el origen a un individuo incapaz de expresarse correctamente en griego. Era en efecto una onomatopeya imitativa para reproducir la dicción de los̀ tartamudos o de los jóvenes y que se encuentra en las palabras "parloteo" "balbuceo", "farfullar". Con ello, Heródoto muestra la importancia que los griegos asignan al logos en su propia caracterización.

He escogido este ejemplo, casi fundador, para llamar nuestra atención sobre dos puntos esenciales, desde mi punto de vista: la de sí

- La caracterización del otro está ligada a

- Ésta se hace a menudo sobre la base del lenguaje y especialmente de la pronunciación

En cuanto a la localización de la diferencia en la pronunciación y más generalmente en la manera de hablar, coexiste con la variación. En la medida en que toda lengua declina las variaciones, estas variantes, producto de la evolución interna diferenciada pero también de la diversificación social, se transforman en marcas: entran también en el sistema de la semiótica social.

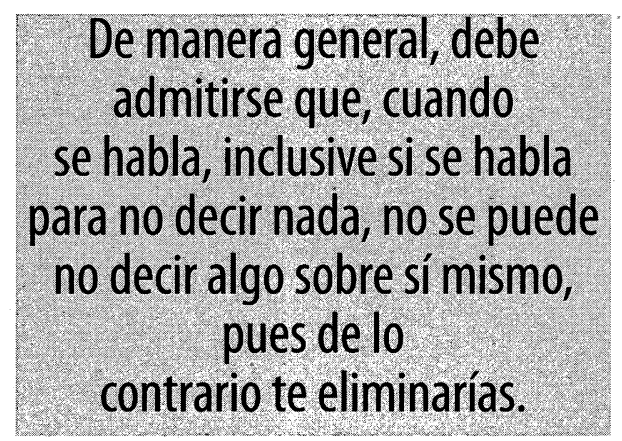

Hemos subrayado que esta base no es solamente social. La manera de hablar (o por otra parte de no hablar) (el estilo, la variación diafásica) nos informa también sobre la persona misma: sobre su sexo, su edad y también sobre sus disposiciones de ánimo permanentes (carácter, timidez) o temporales (cólera).

De manera general, debe admitirse que, cuando se habla, inclusive si se habla para no decir nada, no se puede no decir algo sobre sí mis- mo, pues de lo contrario sería una eliminación de sí mismo.

\section{Percepción y categorización}

La percepción y el reconocimiento de un acento en el otro es una operación que se acompaña de una categorización de su locutor: se tendrá el acento portugués, diferente del acento brasileño, etc. Es decir la puesta en relación, la atribución de una marca (que reposa en el significante) y de un grupo. La categorización descansa sobre tres funciones:

- la denominación

- la atribución de rasgos definitorios de la clase

- la evaluación.

Se considera que la categorización forma parte de la semiótica, y se apoya material y per-. ceptivamente en formas retenidas como signos integrados en una estructura social e interpretativa compartida. El acento, como lo hemos dicho, no es sino una de las formas observables sobre las cuales se apoya el proceso de categorización. Aunque hay otras: vestidos, gestos, posturas, etc. Un rasgo es marcado (una manera de saludar, por ejemplo) y este rasgo envía a una estructura de significación compartida, grupos de pares, por ejemplo, que son identificados y se identifican gracias a ese rasgo. Pero lo arbitrario del signo, unido a su naturaleza simbólica, permite la adaptación y la evolución del sistema: una forma de saludo puede ser reemplazada por otra, o bien ser desplazada hacia otra significación.

En Francia, el saludo musulmán en el que se golpea el pecho a nivel del corazón después de haber tocado la mano de su interlocutor, es utilizado por jóvenes no musulmanes. Ciertos términos antiguos del argot de los ladrones cuya función era secreta al comienzo (un poco como el lunfardo argentino) han pasado al lenguaje de los jóvenes y han tomado una función simbólica que no tiene nada de secreta, sino al contrario: se ha vuelto un signo ostentatorio, puesto que pasó del secreto, en su origen, a ser una marca emblemática. Hay un paso de lo privado (entre nosotros) a lo público, un acto de construcción 
identitaria por el uso de los gestos y de términos escogidos en un proceso de "refuncionalización": una misma marca lingüística, utilizada en una época ulterior, o en un contexto diferente, ve evolucionar su función social (es lo que tratan los lexicógrafos y los historiadores de la lengua).

\section{La construcción identitaria en los relatos sobre sí}

Mi último ejemplo está tomado de una entrevista con una joven que, en el momento de la grabación, había vivido veinte años en Francia. Se busca a partir de este explorar la noción de identidad narrativa que nos ha legado Paul Ricoeur conservando la postura dialógica de Bajtin (1979).

R. Roselyne, estudiante institutriz, de 25 años, nació en Argelia y llegó a Francia a la edad de seis años con su madre, para unirse a su padre, en el momento de la fuerte inmigración argelina. La entrevista con $\mathrm{R}$ se realizó en francés y se refiere a su biografía lingüística y a la relación entre lengua e identidad. Su disçurso se construye tomando como referencia las ideas contradictorias recibidas sobre el árabe en Francia.

En el siguiente ejemplo $\mathrm{R}$ responde a una pregunta hecha por la entrevistadora (Ro) relacionada con el rechazo de algunas personas a la lengua árabe.

R. - ¿Y por qué yo la rechazaría? Es porque la gente... Es una bella lengua, la gente se burla, pero es una lengua muy pulida, llena de metáforas, es por eso que yo quiero aprender el árabe... literario ${ }^{2}$. Es la cultura, sus orígenes, y pues es la carta de presentación para un trabajo. No es porque los medios de comunicación hagan burlas. Tengo la impresión, sólo es una impresión...

“YY por qué yo la rechazaría?” ¿A quién se dirige esta pregunta relacionada con la lengua árabe? Con este enunciado interrogativo y negativo a la vez, $\mathrm{R}$ se amonesta a sí.misma o se incluye en el auditorio que reprocha al grupo

\footnotetext{
2 Árabe literario diferente del árabe dialectal, que es únicamente hablado.
}

evaluado negativamente "la gente" y sobre todo "la gente que se burla". Ella propone enseguida una serie de evaluaciones positivas de la lengua (bella, pulida, llena de metáforas, es la cultura, sus orígenes, es una carta de presentación para un trabajo) mezclando valores estéticos, simbólicos e instrumentales. Nos convida como Heródoto a construir en cruz el pensamiento del adversario del cual toma las contradicciones. La

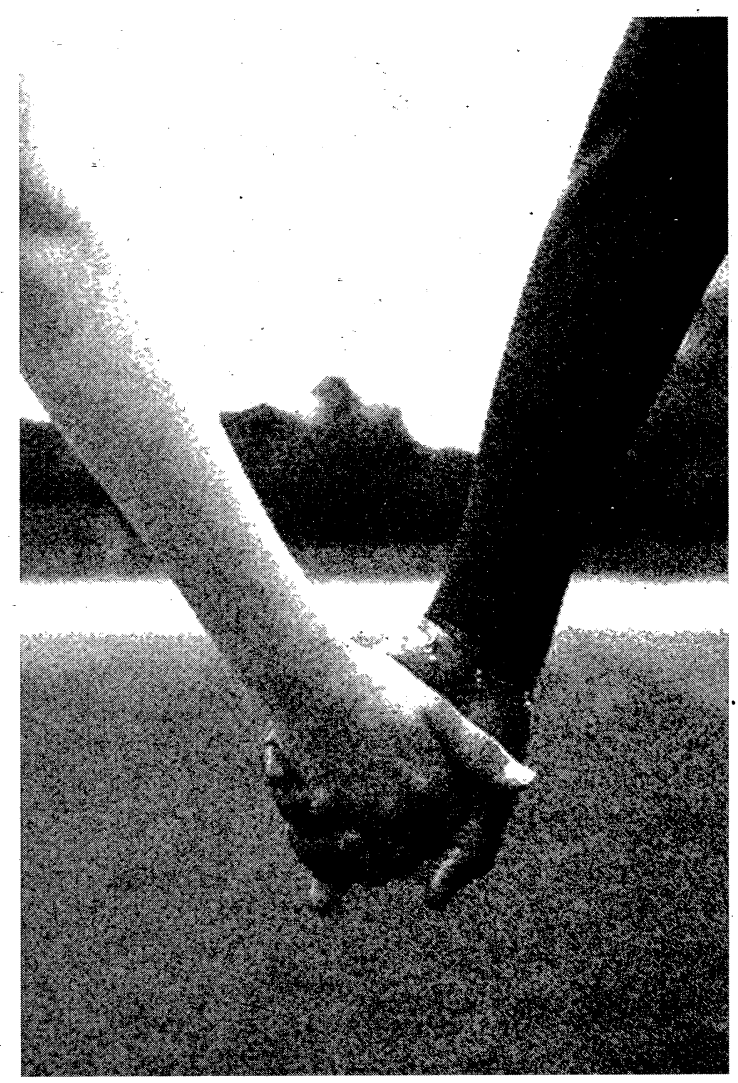

aparición de la tercera persona en "sus" orígenes, la sitúa en la palabra de otro o en un pensamien-. to general.

Tengo la impresión que la época... es... tú ves un árabe es un extremista, tú ves un árabe es un terrorista. Para mí, tengo la impresión que este siglo, en fin el año 2000, los árabes son el veneno. Tengo la tendencia a protegerme, a sobreprotegerme aunque eso no debería ser así.

R. pasa de la lengua al grupo y recuerda la estigmatización de que han sido objeto después del 11 de septiembre, de parte de "tu", pronombre bastante ambiguo, ligado a su interlocutora, al lector, también al racista denunciado. Es a través del eco y el juicio de diferentes voces (por 
el uso sabio del discurso indirecto libre) que la joven va a construir poco a poco, cada vez de manera más precisa, la relación entre lengua e identidad y a circunscribir su propia identidad en este relato dialogado:

Ro. Tú dices los árabes...

R. Bueno, sí, uno dice los árabes

Ro. Tú no dices "los argelinos", tú dices los “árabes”, ¿Qué es ser árabe, qué es ser “argelino"?

R. Para mí, en efecto, árabe, es la lengua. Es todas las personas que hablan árabe.

La entrevistadora (Ro) retoma sus propósitos citándolos (discurso semiindirecto): "tú dices", el cual es inmediatamente reformulado por R. en "uno dice". Cambiando el pronombre (tú dices>>uno dice), ella inscribe su discurso en la intertextualidad, es decir, en una respuesta a un discurso anterior e introduce con ello una responsabilidad diferida hacia "uno".

En el juego "tú dic̀es/ tú no dices", Ro introduce la polémica de las oposiciones para preguntar, de manera insistente, una definición de las categorías "árabe", "argelino" (término que podría ser sustituto de "árabe", puesto que introduce un paradigma). Ella obtiene una definición personal de parte de su interlocutora donde la categoría "árabe" reposa sobre la lengua exclusivamente. De esta manera descarta las categorías políticas producidas en los medios (extremista, terrorista) oponiendo su discurso y su acepción relacionada con las armas.

\section{Conclusiones}

Con estos dos ejemplos, el acento y la categorización de los relatos de sí, hemos querido ilustrar una concepción constructivista de las identidades considerando a los locutores como actores permanentes en los procesos de construcción y realización discursiva. Insistimos también sobre el hecho de que esta construcción identitaria se realiza sobre "lo ya dicho", es decir, a partir de las marcas, de los enunciados anteriores, de las categorizaciones corrientes que le conviene a cada uno re-trabajar en el discurso con el otro, en el diálogo polifónico, sin cesar recomenzado entre sí y los otros. Ó

\section{Bibliografía}

BAJTIN, M. (1979). Le marxisme et la philosophie du langage. Minuit, Paris.

BARTHES,

BOURDIEU, Pierre (1982). Ce que parler veut dire. Fayard:Paris.

CORREIA Helena et Margaret BENTO (1997) "Les effects du retour définitif pour les migrants de la seconde génération sur quelques variables phonologiques du portugais en milieu rural", Actes du colloque de la SILF, Université de Coimbra (Portugal): Paris, P.U.F.

FRANÇOIS, Frédéric (1990). La communication inégale. Delachaux et Niestlé. Paris.

GERGEN, Kenneth, 1997. El yo saturado. Dilemas de la identidad en el mundo contemporáneo. Paidós. Barcelona. 370 p.

GOFFMAN, Erving, 1973, La mise en scène de la vie quotidienne. I La présentation de soi. Les éditions de Minuit. Paris 251.

HART'OG, François (1980). El espejo de Heródoto. Ensayo sobre la representación del otro. Paris.

LEVI-STRAUSS, Claude (1962). La pensé sauvage.

RICOEUR, Paul (1990) Soi-même comme un autre, Paris, edt. Du Seuil.

WHORF, Benjamin (1956). Language, thought and reality: selected writings, ed. John $\mathrm{Ca}-$ rroll, Cambridge, Mass. 